- 0,10 a 0,50 por dia, e, nos casos graves até 1 gr. e da digital:na crystallizadia $1 / 2$ a 1 milligrammo (1 milligrammo!), pois conhecendo-se bem estas doses, com a equivalencia em acção para as folhas e para os principios activos, isto é, para a digitalina, podemos calcular bem as doses destes multiplos preparados, conhecidos as respectivas equivalencias que consignam os prospectos,

(Continua no proximo numero):

\title{
Das condições em que actualmente se encontram os surdos-mudos no Brasil.
}

E nosso intuito apresentar e criticar a estatistica de surdos mudos realisada conjunctamente com o recenseamento geral de 1920, e fazer tambem algumas considieraçães sobre o que temos realizado em favor desses infelizes.

Com referencia a estatistica, temos a considerar que não se trata de uma estatistica medica propriamente dita; entretanto tem ella o merito de demonstrar o grande numero de surdos mudos' que 'existem em nosso paiz, e fornecer algumas ourtas informações uteis a iquem estuda o assumpto.

O fim principal de uma estatistica medica de sundos mudos é a indagação das causas directas e indirectas da surdo mudez, para, suipprimindo-as, evitar o alastramento do mal. $\mathrm{Na}$ nossa estakistica official apenas foram contados os surdos mudos existentes no paiz, sem pesquizar a nenhuma daquellas causas, sendo esta propria contagem passivel de alguma critica.

Pela nossa estatistica verificamos que existem no Brasil 26.214 surdos mudos, dandio relativamente a população total die 30.635.605 hab., a proporção de $8,56: 10.000$, ou seja 1 surdo mudo para 1.168 habitantes, mais ou menos. 
Nos dois quadros seguintes damos o modo pelo quial se distribuem estes surdos mudos pelos differentes Estadios e rias respectivas Capitaes, e o numero proporcional de surdos mudos para 10.000 hab, em cada Estado e em cada Capital, numero este sem duvida muito mais importante e mais interessante que o numero absoluto. Um estado como Minas Geraes, p. ex., com um numero elevadissimo de surdos mudos (9.589), tem relativamente um numero muito menor de surdos mudos que o Estado de Matto-Grosso, que tem apenas 556 surdos mudos.

\begin{tabular}{|c|c|c|c|}
\hline \multicolumn{2}{|c|}{ ESTADOS } & $\begin{array}{c}\text { Propopgẽão para } \\
10.000 \text { hab. }\end{array}$ & $\begin{array}{l}\text { Numero de } \\
\text { Surdos-Mudos }\end{array}$ \\
\hline \multicolumn{2}{|c|}{ Goyaz . . } & 54,05 & 2.767 . \\
\hline \multicolumn{2}{|c|}{ Matto Grosso } & 22,55 & 556 \\
\hline \multicolumn{2}{|l|}{ Paraná } & 17,03 & 1.168 \\
\hline \multicolumn{2}{|c|}{ Minas Geraes . } & 16,29 & 9.589 \\
\hline \multicolumn{2}{|c|}{ Districto Federal } & 10,71 & 1.240 \\
\hline \multicolumn{2}{|c|}{ Santa Catharina } & 8,04 & 538 \\
\hline \multicolumn{2}{|c|}{ R. G. do Sul .. } & 7,82 & 1.707 \\
\hline \multicolumn{2}{|c|}{ São Paulo } & 5,86 & 2.690 \\
\hline \multicolumn{2}{|l|}{ Piauhy } & 5,75 & 350 \\
\hline \multicolumn{2}{|c|}{ Maranhão } & 5,74 & $5(12$ \\
\hline \multicolumn{2}{|c|}{ Rio Grande do Norte. } & 5,36 & 288 \\
\hline \multicolumn{2}{|c|}{ Parahyba } & 5,16 & 496 \\
\hline \multicolumn{2}{|l|}{ Bahia . } & 4,44 & 1.482 \\
\hline \multicolumn{2}{|l|}{ Sergipe } & 4,38 & 209 \\
\hline \multicolumn{2}{|c|}{ Ceará . . } & 4,07 & 537 \\
\hline \multicolumn{2}{|l|}{ Espirito Santo . } & 3,94 & 180 \\
\hline \multicolumn{2}{|l|}{ Alagôas . } & 3,70 & 362 \\
\hline \multicolumn{2}{|l|}{ Amazonas } & 3,63 & 132 \\
\hline \multicolumn{2}{|c|}{ Pará . . } & 3,42 & 336 \\
\hline \multicolumn{2}{|c|}{ Rio de Janeiro. } & 3,34 & 521 \\
\hline \multirow{2}{*}{\multicolumn{2}{|c|}{$\begin{array}{l}\text { Pernambuco } \\
\text { Acre }\end{array}$}} & 2,54 & 547 \\
\hline & . & 1,84 & 17 \\
\hline Acre & & 8,56 & 26.214 \\
\hline
\end{tabular}




\begin{tabular}{|c|c|c|c|c|}
\hline \multicolumn{3}{|c|}{ CAPITAES } & $\begin{array}{l}\text { Рророре̨а̃o papa } \\
\text { t0.000 habitantes }\end{array}$ & $\begin{array}{l}\text { Numero de } \\
\text { Surdos Mudos }\end{array}$ \\
\hline Goyaz . & . & . & 65,02 & 138 \\
\hline Cuyabá . & . & . & 53,45 & 180 \\
\hline Victoria. & . & . & 6,86 & 15 \\
\hline Bello Horizont & & . & 6,30 & 35 \\
\hline Curytiba. & : & . & 5,82 & 46 \\
\hline Manáos. & . & - & 3,96 & 30 \\
\hline São Paulo & - & . & 3,89 & 225 \\
\hline Florianopolis & . & . & 3,63 & 15 \\
\hline Porto Alegre & . & - & 3,07 & 55 \\
\hline Maceió . & - & - & 2,97 & 22 \\
\hline S. Salvador & . & . & 2,82 & 80 \\
\hline Nicteroy. & . & . & 2,55 & 22 \\
\hline São Luiz & . & • & 2,46 & 13 \\
\hline Therezina & . & . & 2,43 & 14 \\
\hline Aracajú. & · & - & 2,14 & 8 \\
\hline Parahyba & . & . & 2,08 & 11 \\
\hline Belém . & . & . & 1,69 & 40 \\
\hline Recife . & $\cdot$ & - & 1,30 & 31 \\
\hline Fortaleza & . & - & 1,27 & 10 \\
\hline Natal & . & . & 0,98 & 3 \\
\hline
\end{tabular}

Observando o primeiro destes dois quadros, vemos que a proporção de surdos mudos em relação a pepulação geral, é muito menor mos estados do norte que nos do sul e do centro. $\mathrm{O}$ maximo nós observamos no Estado de Goyaz que apresenta a proporção bastante elevada de $54,05: 10.000$, e principalmente em sua Capital, onde esta proporção eleva-se a $65,02: 10.000$, ou seja approximadamente 1 surdo mudo para 154 habitantes, o que é verdadeiramente espantoso. Tal proporção nunca foi encontrada nem na Suissa, que é o paiz que proporcionalmente tem maior numero de surdos mudos $(25,4: 10.000)$, nem em certas 
provincias austriacás onde a proporção é de 1 surdo mudo para 200 habitantes, e que era considerada a mais elevada até agora encontrada em uma população.

Qual șerá a causa da differença de proporção que encontramos entre os estados do norte e os estados do sul e do centro?

Entrarão ahi em jogo os factores clima, altitude, temperatura, constituição do sólo ou da agua, que segundo alguns auctores tem grande influencia na producção da surdo mudez? Será que as populações dos es* tados nortistas vivem em melhores condições sọciaes e hygienicas que as dos demais estados?

Eis ahi duàs questõés que sómente um inquerito apurado poderiá resolver.

Dos 26.214 surdos mudos existentes no Paiz, 7.937 são menores de 15 annos, e18.277 maiores desta edade; 25.57.4 nacionaes, 636 extrangeiros, e 4 de nacionalidade ignorada; 14.525 são do sexo masculino e 11.689 do sexo feminino, dando uma relação de 100 surdos mudos do sexo masculino, para 80,5 do sexo feminino, o que aliás está de "perfeito accordo com as estatisticas dos demais paizes, onde sempre se tem verificádo uma sensivel predominancia dos surdos mudos do sexó masculino, mesmo em paizes como a Noruega, onde o numerb total de mulheres é sensivelmente superior ao de homens.

Muitas 'sãc as causas de erro a que uma estatistica deste genero estŕá sujeita, e que no caso presente não se procurou afastar.

Em primeiro logar temos a ignorancia e a má vontade do povo em auxiliar os recenseadores. Poucas são as pessoas que alcançam os fins de um estatistica e os beneficios que della podóm advìir a colelctividade. Para grande parte do povo receseamento quer dizer recrutameñto, e dahi informações poúco exactàs, simulação de surdez e de outros defeitós physicos, com o fim unico de escapar ac serviço militar, que infelizmente é o) pesadelo de quasi todos os nossos jovenis patricios.

A grande dispersão em que se encontram os surdos mudos, e os pessimos mieos de conducção que em geral possuimos, tambem são "factores que muito contribuem para a defficiencia da estatistica. Por es- 
tas razões o recenseamento de certas regiōes ficou muito imperfeito, havendo grandes falhas que contribuiram bastante para alterar o resultado da estatistica.

Sómente o ensino obrigatorio, que centralizaria os surdos, mudos, permittiria estatisticas correctas, pelo imenos daquelles que estivessem em edade escolar.

Outra importante causa de erro, resulta do recenseamento haver sido feito por pessoas completamente leigas sobre o assumpto, e que não receberam à minima instrucção á cerca da maneira que deveriam procẹider para com os surdos mudos, conforme se poderá julgar pelas instrucções expedidas aos recenseadores. A partic pação de technicos ma compilação desta estatistica, viria supprimir grande parte dos erros que ella encerra.

Citarei um caso succedido na cidade Joinville no estado de Sta. Catharina, pelo qual se poderá julgar ıda competencia dos nosșos recenseadores sobre o assumpto. - Ulm inspector de quarterão encarregado do recenseamento, recursou registrar um surdo mudo como tal, unicamente porque este fallava tão bem como qualquer outra pessoa; entretanto tratava-se de um rapaz que soffria de surdez total congenita, e que aprendera a fallar devidio aos esforços de um parente seu.

Perguntamos se foram recenseados os surdos mudos de menos de 3 annos de redade. Acreditamos que não. Ordinariamente se está longe de "proceder a provas de audição em creanças desta edade, e os paes só começam a desconfiar da surdez dos seus filhos quando elles attingem os 2 ou 3 annos sem que aprendam a fallar.

Só esta causa de erro é sufficiente para diminuir de $20 \%$ ou mais, o numero de surdos mudos com menos de 15 annos de edade. Wilde em 503 casos de surdo mudez, constatou a surdez até os 3 annos em 120 casos, e nós mesmo, temos algumas observações de surdos. mudos com menos de 2 annos de edade. Geralmente o diagnostico de surdez em creanças de tenra edade não é facil, sendo necessaria a interferencia de um especialista.

$\mathrm{Na}$ organisação desta estatistica procurou-se definir o que seja um surdo murdo?

Esta noção a prìmeirá vista bastante clará, parece aindà não estar bem assentada. 
Temos os verdadeiros suirdos mudos que são aquelles que não ouvem absolutamente nada, ou aquelles que devido a grandies falhas de audição, ou por a terem muito diminuida, não puideram aprender a linguagem pela audição ;em caso da sundez ser adquirida, é necessario que o accidente ou molestia que a acarretou, haja occorrido antes dos 8 annos de edade, pois em caso contrario, o individuo não esquecerá jamais a palavra aprendida, tornando-se então simplesmente surdo, mas não mudo.

$\mathrm{Ha}$ muitos surdos mudios que ouvem perfeitamente certos sons ou ruidos, chegando alguns mesmo a distinguir syllabas, sem que entretanto tenham capacidade para aprender a linguagem fallada pela audição. Estes surdos mudos em geral, não são considerados como tal pelo povo.

$\mathrm{Ha}$ ao contrario individuos moucos, isto é, que tem a audição muito diminuida para todos os sons, e que entretanto tem capacidade para aprender a linguagem fallada pela audiçãa.

Bezold classifica ccmo surdo mudo todo o individuo que devido a falta de audição, não possa ser educaldo do mesmo modo que os individuos normaes.

A lei na Allemanha, determina como surdos mudos, todos os individuos mudos e completamente surdos, ou aquelles que tenham uma audição tão diminuida, de modo a não poderem aprendẹ a liguagem pelos meios naturaes, e que inão sejam capazes de comprehender pela aúdição a linguagem que aprenderam. Esta lei serve de base as estatisticas de surdos mudos na Allemanha, fixando e unificando o termo sur-. do mudo.

A lei norte americana idetermina como surda muda toda a pessoa completamente surda até 8 annos de edade, e aquellas maiores desta edade que tenham ficado surdas por accidente ou molestia antes da'quella edade; as pessoas são consideradas surdas quando não percebem a vóz de conversação, ou quando não tem a attenção attrahłda pela vóz, trạtando-se de creanças de tenra edade.

Foi feita uma distinção segura entre os idiotas e os surdos. mudos?. Julgamos que não. Commummente' o vulgo confunde o idiota com o surdo mudo. O idiota geralmente ouve muito bem, mas devido a -insufficiencia intellectual, não é capaz de manifestar seu pensamento nem ao menos por meio de gestos, ao passo que o surdo mudo, mesmo quando. não instruidio, o representa por meio de gestos, pois no geral os surdos mudos são individuos de intelligencia muito lucida. A unica anormalida- 
de que encontramos no surdo mudo verdadeiro, é para o lado do apparelho da aưdição

Estamos tambem certos da grande confusão que houve entre surdos mudos e os simplesmente aphasicos, que com certeza, em grande numero tambem foram arrolados como surdos mudos.

'E necessario que o termo surdo mudo tenha uma definição unica e precisa em toda a parte, afim de que possamos obter numeros exactos e equivalentes. Para a elaboração desta estatistica, estamos certos que não houve tal. Estando a determinação do que seja um surdo muldo a cargo de cada um dos recenseadores, não podemos nem ao menos attribuir equivalencia entre as cifras recolhidas nos diversos estados.

Em prova de falta die criterio com que até agora se tem feito as estatisticas deste genero aqui no Brasil, temos as formidaveis differenças que observamos nos numeros de surdos mudos em relação a população, nos recenseamentos de 1872, 1900 e 1920. Em 1872 a proporção era de 11,47:10.000 habitantes; em 1900, 28 annos mais tarde, esta proporção foi reduzida a terça parte $-4,25$. 10.000; agora no recenseamento de 1920, verificamos que ella subiu a $8,56: 10.000$. São curiosas estas grandies differenças nos relativamente, curtos prazos de 28 e 20 annos. Talyez houvesse mais alguma surpreza, si houvesse sido publicada a parte do recenseamento de 1890 relativa a surdo mudez.

Vemos portanto que esta estatistica tem pouco merito devido ás grandes causas de erro que muito a alteram, e nenhum valor medico scientifico por ser muito defficiente.

Dando por certa a estatistica de surdos mudos de 1920, vemos que existem no Brasil cerca de 27.000 surdios mudos, pelos quaes ainda nada se fez, estando elles completamente entregues ao seu destino, no mais miseravel abandono.

Em todos os paizes do mundo têm sido os surdos mudos considerados com à maxima attenção e carinho por parte dos Governos e das associações philantropicas, sempre dispostas a amparar as causas boas $e$ justas. Em muitos paizes as instituições para sưrdos mudos são vendadeiramente modelares, amparando-os em todos os periodos de sua vida. Deixando de parte paizes como a Allemanha, a Austria, a França e os Estados Unidos, que possurem instituições formidaveis e perfeitas, ternos 
muito proximos de nós, na Capital do Chile uma instituição que muito honra a esse paiz, com capacidade para instruir a todos os seus surdos mudos em edadie escolar.

Nós, que possuimos um tão elevado numero de surdos mudos, muito pouco temos feito para lhes melhorar as condições de vida.

Temos na Capital da Republica um grande Instituto para Surdos Mudos, installado em magnifico predio de enorme capacidade, funccionando porém com um diminuto numero de alumnos, 30 ou 40 . Grande parte do predio é occupado pela repartição de Serviço de Protecção aos Indios e Trabalhos da Comissão Rondon.

Temos aqui em São Paulo um pequeno Instituto particular funccionando com cerca de 40 alumnos, porém defficientemente installado e mantido exclusivamente pelos esforços do seu director.

Existe tambem na cidade de Itajubá (Minas) um recolhimento para moças surdas mudas (apenas recolh imento, não escola), mantido pela piedade das freiras de um convento lá existente.

Fóra estas pequenas e defficientes instituições, ao que saibamos, nada mais possuimos, isto em um paiz onde existem 27.000 surdos mudos! Melhor seria dizer que praticamente nada temos.

O surdo mudo não é actualmente mas considerado como outróra, um ente incapaz, inferior, quasi irracional, destinado ao sacrificio da morte ou do trabalho forçado, condemnado até pelo christianismo como incapaz de possuir a fé christã.

A moderna concepção do surdo mudo é muito outra: tem-se verificado que o surdo mudo é intelligente, avido de aprender, a espera somente de mão generosa que o auxilie a sahir da tréva em que vive; aprende tudo com muita facilidade - a ler, a escrever, dedica-se com afinco a uma profisão que lhe garanta a subsistencia. O surdo mudo aprende a fallar, cousa que a mu tos parece incrivel e espantosa.

São elles accusados de ingratidão, e de serem elementos degenerados e degeneradores da raça. Serão estas razões sufficientes para que os deixemos ao abandono? Não seria muito mais racional e muito mais humano emprehender uma verdadeira campanha prophylactica da surdo mudez, quer sob o ponto de vista social, quer sob o ponto de vista medico propriamente?

Enconitramos dez vezes' mais sundios mudos mos, dificendentes de un ões consanguineas, que entre os descendentes de surdos mudos. Onde estará o maior perigo? 
Temos 27.000 individuos completamente inuteis a si proprios e bastante onerosos a sociedade a espera da rehabilitação.

E promover a sua rehabilitação seria muito mais que ıma obra grandemente piedosa e humanitaria - seria uma obra extraordinariamente patriotica.

ARNALDO BACELLAR.

\title{
Conferencia de terapeutica clinica
}

\section{Tratamento das Anemias}

\author{
pelo Dr. Ulysses Paranhos \\ (Conferencia realisada, no dia 2 de Maio, na II Enfermaria \\ de Medicina de mulheres do Hospital da Misericordia.)
}

Senihores,

Aproveitando um caso classico, de anemia, que se encontra recolhido á nossa enfermaria, vamos nos occupar, durante alguns momentos, com o tratamento desse sindroma, tão commum na clinica civil e hospitalar.

Os sindromas anemicos são caracterizados, sobretudo, pela pallidez dos tegumentos, diminuição, das hemacias e da hemoglobina, phenomenos esses determinados ou por uma inhibição da funcção hermo-formadora, ou então por uma hematolyse exagerada, mas não apparente. Pode-se, em summa, definir a anemia - uma alteração da funcção respiratoria do sangue (Jolly).

Nas anemias, a pelle e as mucosas mostram-se descoradias, tanto mais intensamente conforme o grau de depauperamento, sanguineo, descoramento esse que não deve, no entanto, confundir com a coloração particular a certas doenças (nefrite, cancer, tuberculose), denominada ocrodermia e que pode se apreșentar, a despeito disso, ccm a formula sanguinea habitual (Marcel Labibé).

Regista-se hypotensão: pulso pequeno; sopros extra-cardiacos e ruido de piorra nos vasos do pescoço. 